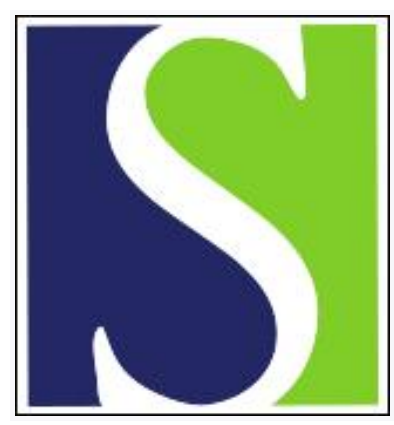

Scand J Work Environ Health 2004;30(1):5-20

https://doi.org/10.5271/sjweh.760

Issue date: Feb 2004

\title{
Relationship between silicosis and lung function
}

by Gamble JF, Hessel PA, Nicolich MJ

Affiliation: 566 Elizabeth Ave, Somerset, NJ 08873, USA. johngamble@patmedia.net

Key terms: diffusion capacity; emphysema; forced expiratory volume in one second; forced vital capacity; gas exchange; lung function; obstruction; quartz; restriction; review; silica; silicosis; smoking

This article in PubMed: www.ncbi.nlm.nih.gov/pubmed/15018024

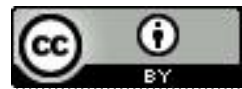




\title{
Relationship between silicosis and lung function

\author{
by John F Gamble, PhD, ${ }^{1}$ Patrick A Hessel, PhD, ${ }^{2}$ Mark Nicolich, PhD ${ }^{3}$
}

\begin{abstract}
Gamble JF, Hessel PA, Nicolich MJ. Relationship between silicosis and lung function. Scand $J$ Work Environ Health 2004;30(1):5-20.

In an examination of the relationship between silicosis and lung function, relevant studies of silica-exposed workers were reviewed. Smoking, dust exposure, and emphysema are three important factors that can confound the association between silicosis and lung function. Despite the importance of smoking in relation to lung function, some studies did not control for smoking, or smoking was controlled inadequately. The data suggest a weak association between lung function (mainly obstruction) and dust exposure, although some studies had crude measures of exposure. In general, the lung function of those with radiographic silicosis in category 1 was indistinguishable from those in category 0.Those in category 2 had small reductions in lung function relative to those with category 0 and little difference in the prevalence of emphysema. There were slightly greater decrements in lung function with category 3 and more significant reductions with progressive massive fibrosis. Emphysema was related to higher categories of silicosis, as well as to smoking. Silica exposure was often inadequately controlled in studies examining silicosis and lung function. A few studies suggested that emphyse$\mathrm{ma}$ is an independent risk factor associated with significant reductions in lung function.
\end{abstract}

Key terms diffusion capacity, emphysema, forced expiratory volume in one second forced vital capacity, gas exchange, obstruction, quartz, restriction, review, silica, smoking.

There is debate about whether changes in lung function among workers with a long history of silica exposure are due to an effect of dust exposure or silicosis (1), or to other factors, possibly nonoccupational. The debate is complicated because (i) silicosis and silica dust exposure are closely related, (ii) silicosis can be present in workers with no radiographic evidence, (iii) smoking is an important determinant of lung function and is often poorly quantified or not considered, (iv) some studies have demonstrated a relationship between silicosis and smoking, (v) the role of emphysema has often not been addressed, and (vi) smoking, dust exposure, and emphysema can all cause obstruction and restriction of lung function and reduce gas diffusion.

We attempted to explore these issues, with primary emphasis on the relationship between reduced lung function and radiographic silicosis. Smoking, dust exposure, and emphysema are confounding factors that are sometimes neither measured nor considered when the role of radiographic silicosis is assessed. We have attempted to account for these factors.
Respiratory impairment or disability is often defined in relation to lung function [especially forced expiratory volume in one second $\left(\mathrm{FEV}_{1}\right)$ and forced vital capacity (FVC)] and dyspnea. Silicosis has been defined as a history of silica exposure and radiological findings of opacities, usually rounded and in the upper-lung zones. Several study designs have been used to examine the relationship between silicosis and lung function. We considered the most informative studies to be those comparing silica-exposed workers with and without silicosis and arising from well-defined cohorts, matched on (or statistically adjusted for) silica (or dust) exposure, smoking, age, and some measure of emphysema, preferably from computed tomography (CT).

In our review of the relevant studies, it became apparent that the lung function tests were conducted in a variety of settings using different equipment, technicians, and prediction equations. Therefore, trends within studies are more interpretable than comparisons across studies. We have focused on the FVC (analogous

1566 Elizabeth Ave, Somerset, NJ 08873, USA.

22 North Riverside Plaza, Suite 1400, Chicago, Illinois 60606, USA.

324 Lakeview Rd, Lambertville, NJ 08530, USA.

Reprint requests to: Dr Gamble, 566 Elizabeth Ave, Somerset, NJ 08873, USA. [E-mail: johngamble@ patmedia.net] 
to a restrictive pattern), $\mathrm{FEV}_{1}$ (analogous to an obstructive pattern), and diffusion capacity $\left(\mathrm{DL}_{\mathrm{CO}}\right)$ or gas exchange. Some of the other spirometric indices were not considered because their variability is much higher than FVC and $\mathrm{FEV}_{1}$.

Searches of Medline and Toxline were conducted using the key words silicosis and lung function. A review of abstracts served as the first screening to identify relevant studies. Final determination was based on whether the relationships between lung function and silicosis were reported. The reference lists of studies were reviewed to identify further studies not found in the computer search.

Relevant studies were considered to be those that presented lung function results by category of radiographic silicosis. These studies were reviewed individually and are presented according to groups with increasing adjustments for confounding by smoking, dust exposure, and emphysema. In each group the studies are presented by study design. A synthesis of the evidence is then presented, including summary results in tables 1-4 and figures $1-3$.

Table 1. Mean percentage of the predicted forced vital capacity (FVC) with its standard deviation in parentheses unless otherwise noted according to the radiographic categories of the International Labour Office (ILO). (CT = computed tomography)

\begin{tabular}{|c|c|c|c|c|c|c|c|c|}
\hline \multirow[t]{2}{*}{ Reference } & \multicolumn{7}{|c|}{ FVC } & \multirow[t]{2}{*}{ Comments } \\
\hline & ILO 0 & ILO $\geq 1$ & ILO 1 & ILO 2 & & ILO 3 & Large opacities & \\
\hline \multicolumn{9}{|c|}{ Studies not adjusting for smoking or other confounding exposures } \\
\hline \multicolumn{9}{|l|}{ Becklake et al, 1958 (2) } \\
\hline $41-50$ years & $106.1(15)$ & . & . & . & & $97.2(15.7)$ & . & \\
\hline $51-60$ years & $113.5(14)$ & . & . & . & & $89.4(13.9)$ & . & \\
\hline Teculescu et al, 1967 (3) & $\begin{array}{l}93.7 \\
\left(84-110^{a}\right)\end{array}$ & $\cdot$ & $89.2\left(79-102^{\mathrm{a}}\right)$ & $86.3(7$ & $\left.76-101^{a}\right)$ & $76.1\left(45-103^{\mathrm{a}}\right)$ & $\cdot$ & \\
\hline \multicolumn{9}{|c|}{ Studies adjusting for smoking but not for dust exposure or emphysema } \\
\hline \multicolumn{9}{|l|}{ Liou et al, 1996 (4) } \\
\hline Nonsmokers & $110(15)$ & $111(19)$ & . & & . & & . & . \\
\hline Exsmokers & $108(19)$ & $106(17)$ & . & & . & & . & · \\
\hline Smokers & $112(22)$ & $107(16)$ & $\cdot$ & & $\cdot$ & & $\cdot$ & $\cdot$ \\
\hline Begin et al, 1988 (1) & $98.8\left(4.1^{\mathrm{b}}\right)$ & . & $87.4\left(4.2^{b}\right)$ & & $85.4(4$ & $\left..0^{\mathrm{b}}\right)$ & $84.4\left(3.4^{b}\right)$ & $\begin{array}{l}\text { ILO 0: no silicosis; } \\
\text { ILO 1: simple silico- } \\
\text { sis by X-ray; ILO } 2 \text { \& } \\
\text { 3: simple silicosis by } \\
\text { X-ray + coalescence } \\
\text { of conglomeration } \\
\text { by CT }\end{array}$ \\
\hline \multicolumn{9}{|c|}{ Studies with some adjustment for smoking and dust exposure } \\
\hline Irwig \& Rocks, 1978 (6) & 4.4 liters & . & 4.50 liters & 4.48 lite & & 3.95 liters & 4.76 liters & \\
\hline Wiles et al, 1992 (7) & $88.9(14.9)$ & . & $95(14.5)$ & $90(13$. & & . & & \\
\hline $\begin{array}{l}\text { Cowie \& Mabena, } \\
1991 \text { (8) }\end{array}$ & $127(17)$ & . & $125(19.7)$ & 122 & 7.9) & $113(21.9)$ & . & \\
\hline Harber et al, 1998 (10) & 103 & 85.2 & 90.6 & 100.2 & & . & . & $\begin{array}{l}\text { Categories } 0 / 0,0 / 1 \text {, } \\
1 / 0 \text { and } \geq 1 / 1 \text { in } \\
\text { place of ILO } 0, \geq 1,1 \text {, } \\
2 \text {, and } 3 \text {, respectively }\end{array}$ \\
\hline \multicolumn{9}{|l|}{ Ng \& Chan, 1992 (12) } \\
\hline Rounded opacities & $3.3(0.4)$ liters & . & $3.2(0.15)$ liters & & $2.9(0.1$ & 17) liters & $2.4(0.17)$ liters & \\
\hline Irregular opacities & . & . & 3.3 (0.07) liters & & $3.2(0.1$ & 15) liters & . & \\
\hline $\mathrm{Ng}$ et al, 1987 (13) & & & & & & & & Adjusted for age at \\
\hline No progression & . & . & $-59(9)$ & $\mathrm{ml} / \mathrm{year}$ & $-73(17$ & 7) ml/year & . & follow-up, pack- \\
\hline Progression & $\cdot$ & $\cdot$ & $\begin{array}{l}-94(10 \\
\text { year }\end{array}$ & 0) $\mathrm{ml} /$ & $-103(1$ & 15) $\mathrm{ml} / \mathrm{year}$ & $\cdot$ & $\begin{array}{l}\text { years and initial FVC; } \\
\text { simple silicosis: ILO } \\
1 \& 2 \text {; complicated } \\
\text { silicosis: ILO } 3\end{array}$ \\
\hline Cowie, 1998 (19) & $\begin{array}{l}-15(75.9) \mathrm{ml} / \\
\text { year }\end{array}$ & . & $\begin{array}{l}-37(97.1) \mathrm{ml} / \\
\text { year }\end{array}$ & $\begin{array}{l}-75(11 \\
\text { year }\end{array}$ & 13) $\mathrm{ml} /$ & $\begin{array}{l}-116(143.3) \mathrm{ml} / \\
\text { year }\end{array}$ & & \\
\hline Koskinen, 1985 (20) & $93(11)$ & . & $82(19)$ & $83(14)$ & & $78(14)$ & $77(14)$ & \\
\hline Moore et al, 1988 (21) & 103 & . & 99 & & 90 & & . & \\
\hline Talini et al, 1995 (22) & 97 & . & 99 & & 96 & & . & \\
\hline \multicolumn{9}{|c|}{ Studies adjusting for emphysema in addition to smoking and dust exposure } \\
\hline Wang \& Yano, 1999 (26) & $96.0(12.8)$ & . & $93.6(2$ & $0.3)$ & & $89.8(18.2)$ & $78.7(22.5)$ & \\
\hline Begin et al, 1991 (30) & $105\left(4^{b}\right)$ & . & $109\left(4^{b}\right)$ & . & & . & . & \\
\hline Begin et al, 1995 (31) & $104\left(3^{b}\right)$ & $110\left(2^{b}\right)$ & . & . & & . & . & \\
\hline
\end{tabular}

\section{a Range.}

b Standard error of the mean. 


\section{Studies not considering smoking}

There were two cross-sectional studies which did not consider smoking in this category.

Becklake et al (2) studied four groups of South African gold miners randomly selected from those who had undergone the compulsory physical and roentgenographic examination in 1955-1956, had worked in the mines for more than 7 years, and had not worked in other mines. Only miners with either normal chest X-rays or those with marked nodular silicosis that was widely distributed throughout the lungs were selected; intermediate groups were excluded. Ten in each group of miners aged 41-50 and 51-60 years were selected for testing. A discriminant analysis was conducted using eight tests that were not significantly correlated and that measured different physiological functions. No single test discriminated satisfactorily between those with normal Xrays and those with advanced silicosis. (FVC was not significantly lower for the miners with silicosis.) About $15 \%$ of those with normal X-rays had functional abnormalities, and $15 \%$ of the miners with silicosis had

Table 2. Mean percentage of the predicted forced expiratory volume in 1 second $\left(\mathrm{FEV}_{1}\right)$ with its standard deviation in parentheses unless otherwise noted according to the radiographic categories of the International Labour Office (ILO). ( CT = computed tomography)

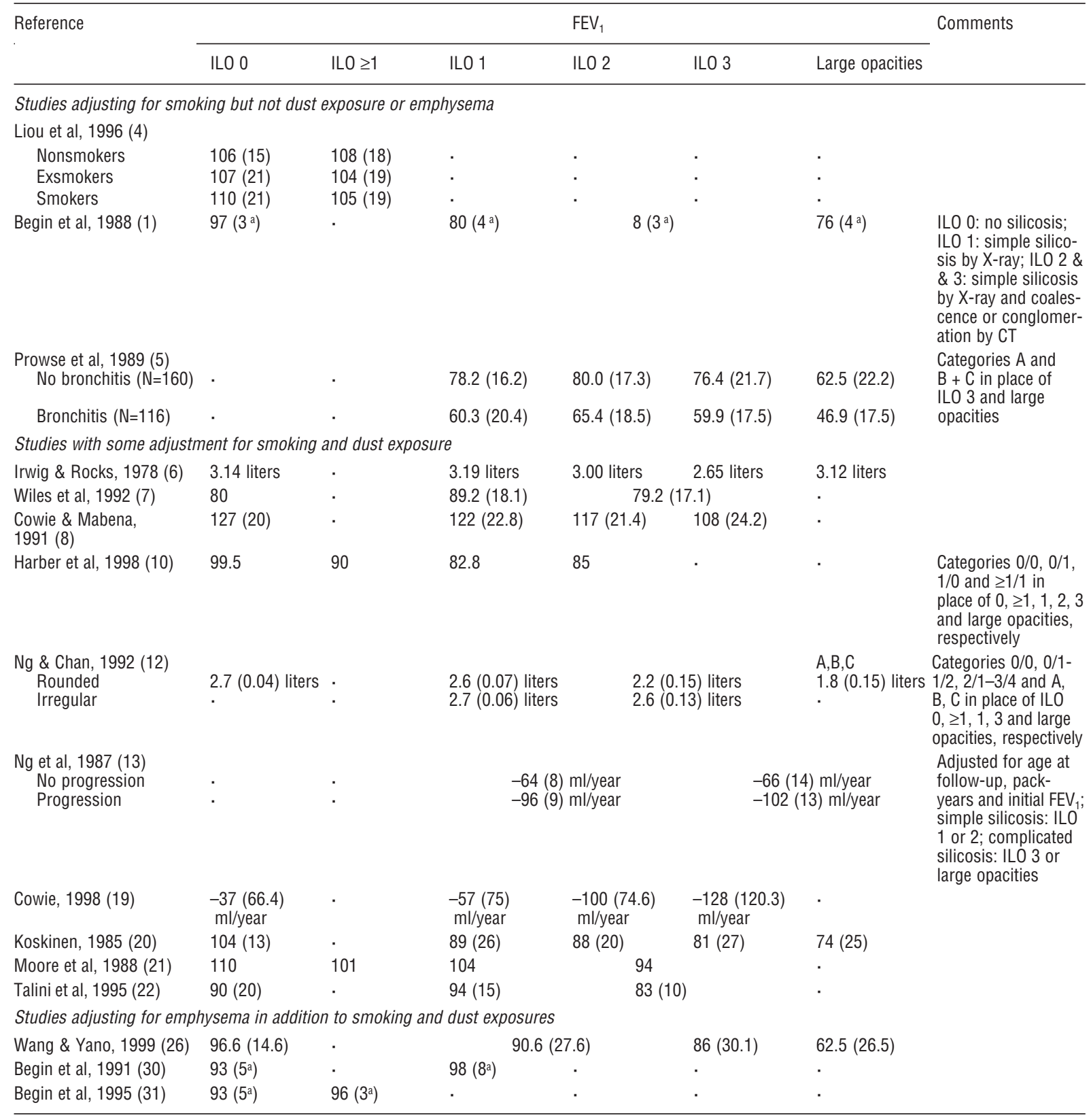

a Standard error of the mean. 
Table 3. Mean percentage of the predicted diffusion capacity $\left(\mathrm{DL}_{\mathrm{co}}\right)$ with its standard deviation in parentheses unless otherwise noted according to the radiographic categories of the International Labour Office (ILO).

\begin{tabular}{|c|c|c|c|c|c|c|}
\hline \multirow[t]{2}{*}{ Reference } & \multicolumn{6}{|c|}{$\mathrm{DL}_{\mathrm{co}}$} \\
\hline & ILO 0 & $\mathrm{ILO} \geq 1$ & ILO 1 & ILO 2 & ILO 3 & Large opacities \\
\hline \multicolumn{7}{|c|}{ Studies adjusting for smoking but not for dust exposure or emphysema } \\
\hline Teculescu \& Stanescu, 1970 (23) & . & . & 105 & 104 & 75 & . \\
\hline Begin et al, 1988 (1) & $105\left(6^{a}\right)$ & $\cdot$ & $94\left(5^{\mathrm{a}}\right)$ & $\begin{array}{l}81\left(6^{\text {a }}\right) \mathrm{ml} /(\text { min. } \\
\mathrm{mm} \mathrm{Hg}) \text { per year }\end{array}$ & $\begin{array}{l}82\left(6^{\text {a }}\right) \mathrm{ml} /(\text { min. } \\
\mathrm{mm} \mathrm{Hg}) \text { per year }\end{array}$ & $\cdot$ \\
\hline \multicolumn{7}{|c|}{ Studies with some adjustments for smoking and dust exposure } \\
\hline Cowie \& Mabena, 1991 (8) & $132(22.5)$ & . & $126(22.2)$ & $122(23.8)$ & $110(27.5)$ & . \\
\hline Cowie, 1998 (19) & $\begin{array}{l}-0.54(1.20) \mathrm{ml} \\
/(\mathrm{min} \cdot \mathrm{mm} \mathrm{Hg})\end{array}$ & . & $\begin{array}{l}-0.89(1.2) \mathrm{ml} \\
/(\min \cdot \mathrm{mm} \mathrm{Hg})\end{array}$ & $\begin{array}{l}-1.22(1.3) \mathrm{ml} \\
/(\mathrm{min} \cdot \mathrm{mm} \mathrm{Hg})\end{array}$ & $\begin{array}{l}-1.37(1.3) \mathrm{ml} \\
/(\mathrm{min} \cdot \mathrm{mm} \mathrm{Hg})\end{array}$ & . \\
\hline Koskinen, 1985 (20) & $99(16)$ & . & $85(23)$ & $82(18)$ & $65(20)$ & $56(13)$ \\
\hline Talini et al, 1995 (22) & $114(11)$ & . & $107(43)$ & $84(34)$ & $\cdot$ & \\
\hline \multicolumn{7}{|c|}{ Studies adjusting for emphysema in addition to smoking and dust exposures } \\
\hline Wang \& Yano, 1999 (26) & 89 & . & 86 & 85 & 74 & . \\
\hline Begin et al, 1991 (30) & $98\left(5^{\mathrm{a}}\right)$ & . & $94\left(4^{a}\right)$ & $\cdot$ & $\cdot$ & . \\
\hline Begin et al, 1995 (31) & $98\left(4^{a}\right)$ & $93\left(3^{a}\right)$ & $\cdot$ & . & . & . \\
\hline
\end{tabular}

a Standard error of the mean.

Table 4. Summary results of individual studies. ${ }^{a}\left(F V C=\right.$ forced vital capacity, $P M F=$ progressive massive fibrosis, $F E V_{1}=$ forced,$C T=$ computed tomography, $\mathrm{DL}_{\mathrm{co}}=$ diffusion capacity, $\mathrm{TB}=$ tuberculosis, $\mathrm{HRCT}=$ high-resolution computed tomography, ILO = International Labour Office)

\begin{tabular}{|c|c|c|}
\hline Reference & Study design & Results \\
\hline \multicolumn{3}{|c|}{ Studies without consideration of smoking } \\
\hline Becklake et al, 1958 (2) & Cross-sectional & FVC: no / 3 \\
\hline Teculescu et al, 1967 (3) & Cross-sectional & FVC: yes / PMF \\
\hline \multicolumn{3}{|c|}{ Studies adjusting for smoking but not dust exposure or emphysema } \\
\hline Liou et al, 1996 (4) & Cross-sectional & FVC: no / PMF; FEV 1 : no / PMF \\
\hline Begin et al, 1988 (1) & Cross-sectional & 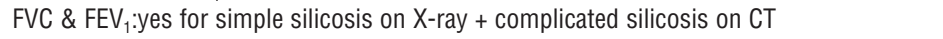 \\
\hline Prowse et al, 1989 (5) & Cross-sectional & FVC: no / PMF; FEV $:$ yes / PMF $(B+C) ; \mathrm{DL}_{\mathrm{co}}:$ no / PMF \\
\hline \multicolumn{3}{|l|}{ Studies adjusting for smoking and dust } \\
\hline Irwig \& Rocks, 1978 (6) & Cross-sectional & 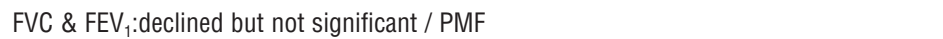 \\
\hline Wiles et al, $1992(7)$ & Cross-sectional & 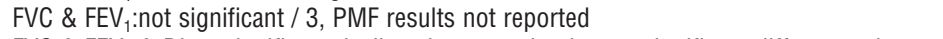 \\
\hline Cowie \& Mabena, 1991 (8) & Cross-sectional & $\begin{array}{l}\text { FVC \& } \mathrm{FEV}_{1} \& \mathrm{DL}_{\mathrm{co}} \text { : significant declines in regression but no significant differences by } \\
\text { category / } 3\end{array}$ \\
\hline Harber et al, 1998 (10) & Cross-sectional & FVC \& FEV ${ }_{1}$ : inconsistent relationships \\
\hline Ng \& Chan, 1992 (12) & Cross-sectional & FVC \& FEV : yes / 2 rounded; no / 3 irregular \\
\hline $\mathrm{Ng}$ et al, $1987(13)$ & Cross-sectional & $\mathrm{FVC} \& \mathrm{FEV}_{1}:$ no / 1 \\
\hline Hughes et al, 1982 (14) & Prospective & $\begin{array}{l}\text { FVC \& } \mathrm{FEV}_{1} \text { : yes by regression, stronger association with dust exposure; } \mathrm{DL}_{\mathrm{co}}: \text { no by } \\
\text { regression, stronger association with dust }\end{array}$ \\
\hline Hnizdo, 1992 (15) & Prospective & FVC \& FEV $:$ no, except for nonsmokers; $100 \%$ attributable to smoking + dust \\
\hline $\mathrm{Ng}$ et al, 1987 (18) & Prospective & $\begin{array}{l}\text { FVC \& FEV } \text { : declines associated with X-ray progression + average silica concentration } \\
+ \text { TB for FEV }\end{array}$ \\
\hline Cowie, 1998 (19) & Prospective & FVC \& FEV 1 : declines associated with silicotic category; largest FEV ${ }_{1}$ declines from TB \\
\hline Koskinen, 1985 (20) & Case-referent & $\begin{array}{l}\text { FVC \& } \mathrm{FEV}_{1} \text { : yes / PMF (no for matched cases and referents; } \mathrm{DL}_{c 0} \text { : yes/ } 3 \text { (no matched } \\
\text { cases and referents) }\end{array}$ \\
\hline Moore et al, 1988 (21) & Case-referent & 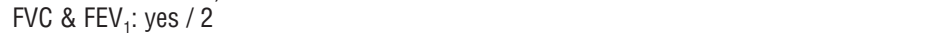 \\
\hline Talini et al, 1995 (22) & Case series & FVC \& DL $_{\text {Co: }}$ no by ILO or HRCT silicosis; FEV ${ }_{1}$ : no by ILO but yes by HRCT silicosis \\
\hline \multicolumn{3}{|l|}{ Studies adjusting for emphysema } \\
\hline Tesculescu \& Stanescu, 1979 (23) & $\begin{array}{l}\text { Cross-sectional } \\
\text { (nonsmokers) }\end{array}$ & $\mathrm{DL}_{\mathrm{co}}:$ yes / PMF \\
\hline Hnizdo et al, 1994 (24) & $\begin{array}{l}\text { Cross-sectional } \\
\text { (nonsmokers) }\end{array}$ & $\begin{array}{l}\text { FVC \& FEV } \text { : possible, but authors suggest that obesity, heart disease and lack of fitness } \\
\text { are more important; silicosis and emphysema uncommon }\end{array}$ \\
\hline Cowie et al, 1993 (25) & Cross-sectional & $\begin{array}{l}\mathrm{FVC}, \mathrm{FEV}_{1} \& \mathrm{DL}_{\mathrm{co}} \text { : no after adjustment for smoking, length of exposure and emphysema } \\
/ 3\end{array}$ \\
\hline Wang \& Yano, 1999 (26) & Cross-sectional & $\mathrm{FVC}, \mathrm{FEV}_{1} \& \mathrm{DL}_{\mathrm{co}}$ : no after adjustment for emphysema (radiographic hyperinflation) / PMF \\
\hline Gevenois et al, 1998 (29) & Cross-sectional & $\begin{array}{l}\text { FVC, } \mathrm{FEV}_{1} \& \mathrm{DL}_{\mathrm{co}} \text { : no / CT categories less than PMF; significant correlations with } \\
\text { emphysema }\end{array}$ \\
\hline Begin et al, 1991 (30) & Cross-sectional & FVC, $\mathrm{FEV}_{1} \& \mathrm{DL}_{\mathrm{co}}:$ no / category 1 by ILO, confluent silicosis by CT, yes for emphysema \\
\hline Begin et al, 1995 (31) & Cross-sectional & FVC \& FEV 1 no / 1 by ILO and yes for CT emphysema \\
\hline Kinsella et al, 1990 (32) & Cross-sectional & FVC \& FEV $_{1}$ : no / confluent silicosis by CT (PMF); yes / CT emphysema \\
\hline
\end{tabular}

a No/ILO category = no significant decrease in lung function / highest ILO category; yes/ILO category = significant decrease in lung function / ILO catecory where significant decrease occurs. 


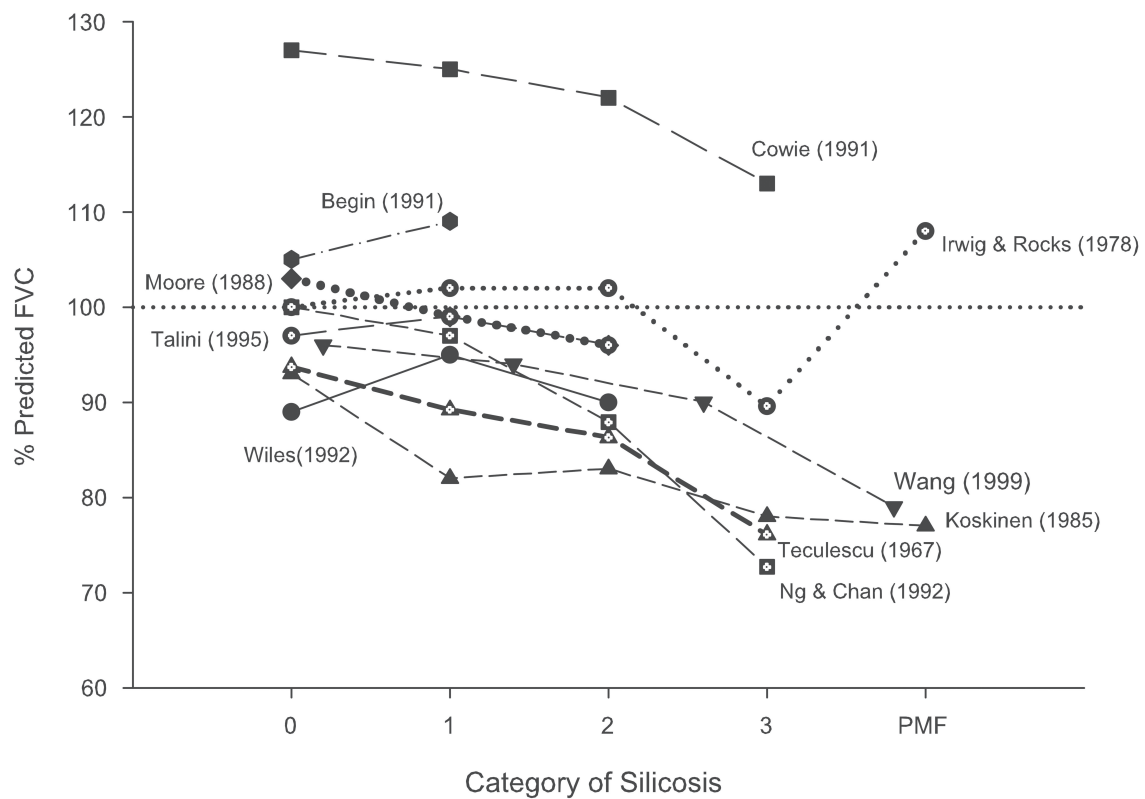

Figure 1. Percentage of predicted forced vital capacity (FVC) by categories of silicosis recommended by the International Labour Organization.

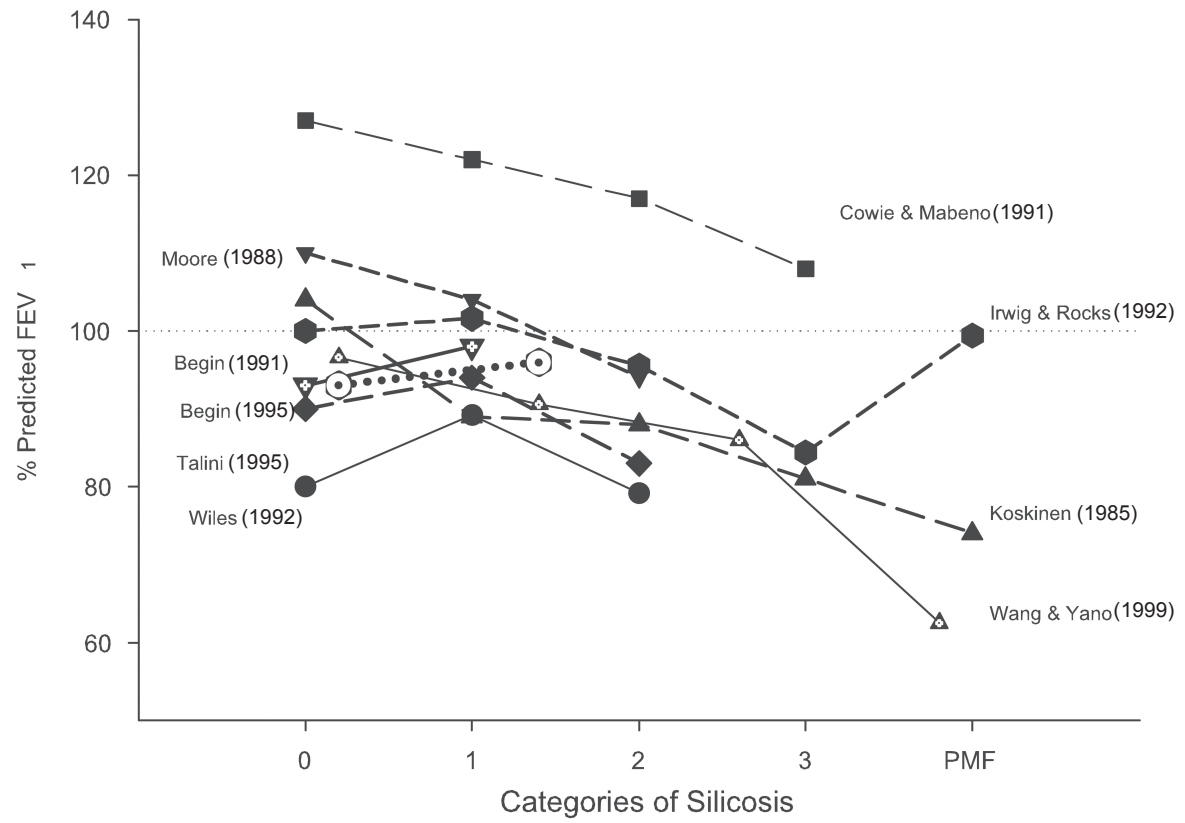

Figure 2. Percentage of predicted forced expiratory volume in 1 second $\left(\mathrm{FEV}_{1}\right)$ by categories of silicosis recommended by the International Labour Organization.

normal function. All eight tests were needed for a fair discrimination of the 41-to-50-year age group, and six tests were needed for the 51-to-60-year age group. Lung function correlated with length of time worked in the dusty rock-breaking service, and the correlation indicated that reduced lung function can occur without frank $\mathrm{X}$-ray evidence of silicosis. There was no apparent association of FVC with silicosis.

Teculescu et al (3) studied a group of 43 hospitalized silicotic patients and 10 healthy patients without silicosis. The silicotic patients were divided into three groups on the basis of the 1958 system of the International Labour Organization (ILO), which we have categorized as 1-2, 3, and PMF (progressive massive fibrosis). Only the PMF group showed obvious decreases in FVC. The ratios of $\mathrm{FEV}_{1}$ to $\mathrm{VC}$ (a measure of obstruction) were reduced and similar in all three groups of silicotic patients.

\section{Studies adjusting for smoking but not dust exposure or emphysema}

The group adjusting for smoking but not dust exposure or emphysema included three cross-sectional studies.

Liou et al (4) compared 526 silica-exposed Chinese firebrick-manufacturing workers with 164 unexposed 